University of Wollongong

Research Online

Faculty of Law, Humanities and the Arts Papers (Archive)

Faculty of Arts, Social Sciences \& Humanities

$1-1-2014$

Hope logics: biomedicine, affective conventions of cancer, and the governing of biocitizenry

Nadine Ehlers

University of Wollongong, nadinee@uow.edu.au

Shiloh Krupar

Georgetown University

Follow this and additional works at: https://ro.uow.edu.au/lhapapers

Part of the Arts and Humanities Commons, and the Law Commons

Research Online is the open access institutional repository for the University of Wollongong. For further information contact the UOW Library: research-pubs@uow.edu.au 


\title{
Hope logics: biomedicine, affective conventions of cancer, and the governing of biocitizenry
}

\begin{abstract}
This essay explores the deployment of hope within biomedicine. Drawing on Michel Foucault's account of biopolitics, it argues that hope works in the service of biopolitical imperatives to govern life, and to secure, optimize, and speculate on that life. The essay broadly considers the operations of affect in biomedicine, and specifically examines the governing function of affective conventions of hope-that is, the perceptual, emotional, and corporeal modes of managing and responding to events that support biomedicine's telos toward the affirmation of life. In relation to illness, hope conditions responses to bodily vulnerability and uncertainty, manages the present for the future, and relentlessly affirms life. The essay grounds these claims in an investigation of cancer activism and treatment, wherein hope is a weapon to fight cancer, as the target of war. Documenting the ways that hope is increasingly militarized, commodified, routinized, and delimited in the neoliberal era, the essay explores how such conventions of hope are actively made and maintained through aspects of cancer-related biomedical encounters-in what it calls infrastructures of care and bioethics of faith within oncology. The essay concludes by considering alternative hope tactics-"hoping for other things"-in relation to cancer.
\end{abstract}

\section{Keywords}

conventions, biocitizenry, affective, governing, cancer, hope, logics, biomedicine

\section{Disciplines}

Arts and Humanities | Law

\section{Publication Details}

Ehlers, N. and Krupar, S. (2014). Hope logics: biomedicine, affective conventions of cancer, and the governing of biocitizenry. Configurations: a journal of literature, science and technology, 22 (3), 385-413. 


\section{PROJECT MUSE}

\section{Hope Logics: Biomedicine, Affective Conventions of Cancer, and the Governing of Biocitizenry}

Nadine Ehlers, Shiloh Krupar

Configurations, Volume 22, Number 3, Fall 2014, pp. 385-413 (Article)

Published by Johns Hopkins University Press

DOI: 10.1353/con.2014.0026

$\Rightarrow$ For additional information about this article

http://muse.jhu.edu/journals/con/summary/v022/22.3.ehlers.html 


\title{
Hope Logics: Biomedicine,
}

\author{
Affective Conventions of
}

Cancer, and the Governing

of Biocitizenry

\author{
Nadine Ehlers \\ University of Wollongong \\ Shiloh Krupar \\ Georgetown University
}

\begin{abstract}
This essay explores the deployment of hope within biomedicine. Drawing on Michel Foucault's account of biopolitics, it argues that hope works in the service of biopolitical imperatives to govern life, and to secure, optimize, and speculate on that life. The essay broadly considers the operations of affect in biomedicine, and specifically examines the governing function of affective conventions of hope-that is, the perceptual, emotional, and corporeal modes of managing and responding to events that support biomedicine's telos toward the affirmation of life. In relation to illness, hope conditions responses to bodily vulnerability and uncertainty, manages the present for the future, and relentlessly affirms life. The essay grounds these claims in an investigation of cancer activism and treatment, wherein hope is a weapon to fight cancer, as the target of war. Documenting the ways that hope is increasingly militarized, commodified, routinized, and delimited in the neoliberal era, the essay explores how such conventions of hope are actively made and maintained through aspects of cancer-related biomedical encounters-in what it calls infrastructures of care and bioethics of faith within oncology. The essay concludes by considering alternative hope tactics- "hoping for other things"-in relation to cancer.
\end{abstract}

Do you know what hope is? It's magic and it's free.

It's not in a prescription. It's not in an IV.

It punctuates our laughter. It sparkles in our tears.

It simmers under sorrows. It dissipates our fears.

Configurations, 2014, 22:385-413 @ 2014 by Johns Hopkins University

Press and the Society for Literature, Science, and the Arts. 
Do you know what hope is? It's reaching past today.

It's dreaming of tomorrow. It's trying a new way.

It's questioning the answer. It's always seeking more.

It's rumors of a break. It's whispers of a cure.

A roller coaster ride. Of remedies, unsure.

Do you know what hope is? It's candy for the soul.

It's perfume for the spirit. To share it makes you whole.

Keep Hope Forever Until We Find A CURE.

—“Banners of Hope"1

\begin{abstract}
"The exercise of power is not a violence that sometimes hides, or an implicitly renewed consent. It operates on the field of possibilities in which the behavior of active subjects is able to inscribe itself. It is a set of actions on possible actions; it incites, it induces, it seduces. ... The exercise of power is a 'conduct of conducts' and a management of possibilities."
\end{abstract}

-Michel Foucault ${ }^{2}$

Hope carries utopian promise; it offers possibilities of a "not yet," a "to come," and an imagining of life otherwise. In contemporary critique, hope has often been deployed as the means to effect radical social transformation and the reinvention of contemporary reality. ${ }^{3}$ It is seen as a way of reaching beyond the stymied conditions of today by orienting toward the horizon of an alternative tomorrow. Hope is invoked as an incantation, under conditions of uncertainty; it is an insistent affirmation of the ability to effect change. This change can be imagined politically and economically, psychologically and corporeally. Indeed, hope is ubiquitous in contemporary culture, from US President Barack Obama's political memoir-The Audacity of Hope-to international food drives-the "Convoy of Hope"4-to biomedical understandings of illness and health. As in the above quotation from "Banners of Hope" (an online outreach for children with life-threatening diseases), hope is the panacea for chronic or terminal illness. Hope might be seen to operate as a logic within the biomedical arena, one that structures subjectivities,

1. See "Final Speech Inspiration's 'Banners of Hope'" on the Sunshine after the Rain blog at http://mbozadji.blogspot.com/.

2. Michel Foucault, Essential Works of Foucault, 1954-1984, vol. 3: Power, trans. Robert Hurley, ed. James D. Faubion (New York: The New Press, 2001), p. 341.

3. See, for example, Mary Zournazi, Hope: New Philosophies for Change (Annandale, NSW, Australia: Pluto Press, 2002).

4. See the Convoy of Hope website at http://www.convoyofhope.org/. 
social realities, and corporeal states. It incites particular behaviors; it induces certain forms of community and belonging; it seduces us to believe in the possible transcendence of bodily limits and/or temporal constraints. As we explore in this essay, hope is the guiding principle of biomedicine's telos toward the affirmation of life.

This essay argues that hope is conventionalized in particular ways that work in the service of biopolitical imperatives to govern life, and to secure, optimize, and speculate on that life. We orient the investigation toward the regulation of affect within the US biomedical arena to consider how affective conventions - that is, the perceptual, emotional, and corporeal modes of managing and responding to events-of hope perform a governing function. ${ }^{5}$ In relation to illness, for example, they condition responses to bodily vulnerability and uncertainty, manage the present for the future, and relentlessly affirm life. We ground these broad claims in an examination of the dominant affective conventions of hope at work in cancer activism and treatment. Documenting the ways in which hope is increasingly militarized, ${ }^{6}$ commodified, routinized, and delimited in the neoliberal era, the essay explores how such conventions of hope are actively made and maintained through aspects of cancer-related biomedical encounters-what we call infrastructures of care and bioethics of faith within oncology. The essay concludes by considering alternative hope tactics- "hoping for other things"-in relation to cancer.

\section{Hope as Biomedical Affect: Biopolitical and Disciplinary Deployments}

Within the "affective turn" of contemporary theory, affect is understood in a range of ways: as immanent to the subject, the pre-discursive or biologized substrate; as that which escapes reason, rationality, and intention; as nonsignifying, formless intensity or vital energy in excess of the human and the social. For example, Eric Shouse,

5. Thus, we focus here on the governing logics of hope, rather than on forms of resistance to such governing. Our interest is to explore how hope is deployed to compel individuals to think about themselves in particular ways, respond to biomedical facts and treatments in specific ways, and act according to dominant biomedical discourses. This is not to say that there are not myriad ways in which individuals and collectives challenge or reject such forms of governing.

6. Our use of the term militarized refers to the general process by which hope has been imbued with martial qualities and practiced across a range of scales for the purposes of security; namely, the organization of life-of institutions, knowledge, and social relations-according to the imperatives of national defense or individual survival, including everyday, banal neoliberal processes that naturalize social inequities and seek to contain social conflict by bounding spaces and bodies. 
referring to Brian Massumi's theory of affect, states that "[a]n affect is a nonconscious experience of intensity; it is a moment of unformed and unstructured potential." ${ }^{7}$ Affect is understood to occur below the threshold of consciousness and cognition, independent of signification and meaning. ${ }^{8}$ It is also seen as "proceeding directly from the body-and indeed between bodies - without the interference or limitations of consciousness, or representation: for this reason, its force is, strictly speaking, pre-personal." ${ }^{\prime 9}$ Such a pre-personal possibility between bodies (or material intensities) is considered to be the space from which a dynamic politics can emerge: "an essentially dynamic, self-organizing biology/nature is presented as the guarantor for an emancipatory and creative politics." 10

An alternative argument, as advanced by Clare Hemmings, is that "affect might in fact be valuable [to criticism] precisely to the extent that it is not autonomous." ${ }^{11}$ This suggests that we can think about affect as actively constructed through representations, practices, and interpersonal relations; as socially and materially arranged; and, importantly, as conditioned through sets of conventions. These conventions organize our affections, sentiments, perceptions, and proclivities; they call on us to generate and cultivate certain responses over others. As such, affect is inextricable from social realities and essential to subjectivity. In contradistinction to the emphasis on affect's immanence in much contemporary scholarship, the point here is to examine the nonimmanent dynamics of affect, and the mechanisms through which affect is deployed within the biomedical and broader social realm. To do so, we employ a poststructuralist framework indebted to Michel Foucault that de-ontologizes emotion and perception to consider the active processes and effects of thinking and feeling.

Multiple affects become solidified through practices and institutions. Importantly, different affects are valued and socially endorsed more than others; some affects become sedimented and thus dominant, while others remain subjugated and contestatory.

7. Eric Shouse, "Feeling, Emotion, Affect," M/C Journal: A Journal of Media and Culture 8:6 (2005). http://journal.media-culture.org.au/0512/03-shouse.php.

8. Ruth Leys, "The Turn to Affect: A Critique," Critical Inquiry 37:3 (2011): 434-472, quote on p. 443.

9. Constantina Papoulias and Felicity Callard, "Biology's Gift: Interrogating the Turn to Affect," Body and Society 16:1 (2010): 29-56, quote on p. 35 (emphasis in original).

10. Ibid., p. 49.

11. Clare Hemmings, "Invoking Affect," Cultural Studies 19:5 (2005): 548-567, quote on p. 565 (emphasis added). 
Furthermore, certain understandings or affective responses are seen as more acceptable than others within the contours of a particular affect. Certain elements of a given affect mark the limits of knowledge and experience of that affect. These complexities call for a nuanced approach to the analysis of affect, one that takes into account the manifold social implications of affective conventions and their material effects. Such an investigation is necessary because of the differential ways that affect forms and conditions bodies, subjectivities, and broader group identities and social relations. The stakes of conceptualizing affect as social rather than ontological are that politics remains embedded in the embodied subjects and critical practices of everyday life.

Affects are productive, in that they form and condition bodies/ selves. We are interested in considering how the affect of hope is deployed in biomedicine, in ways that achieve particular ends or forms of life. Accordingly, the affect of hope can be said to have a governing function. We understand governing function in terms of Foucault's theory of biopolitics, an account of a form of power that governs life-that has "taken control of life in general."12 We are concerned with biopolitical mechanisms-specifically, how hope is deployed within the biomedical field-in ways that come to structure life and discipline subjects. For Foucault, discipline is that set of practices that endows the individual body with capacities and "'makes' individuals; it is the specific technique of a power that regards individuals as both objects and instruments of its exercise."13 This body that is individualized, and the individual that is made, emerges through the exercise of norms and normalizing technologies; and, in this emergence, the subject plays a key role, forming a sense of self in relation to norms. While discipline focuses at the level of the individual, what Foucault calls biopolitics operates at the level of the population and works to achieve the regulatory control of the mass of bodies comprising the population. Foucault argues that this modality of power-biopolitics-takes "the totality of the concrete processes of life in a population ... [as] the target of security" to make the population live (more). ${ }^{14}$ While the two modes of power can be

12. Michel Foucault, "Lecture Eleven: 17 March 1976," in Society Must Be Defended, trans. David Macey, ed. Mauro Bertani and Alessandro Fontana (New York: Picador, 1997), pp. 239-264, quote on p. 253.

13. Michel Foucault, Discipline and Punish: The Birth of the Prison, trans. Alan Sheridan (London: Penguin Books, 1991), p. 170.

14. Thomas Lemke, Biopolitics: An Advanced Introduction (New York: NYU Press, 2011), p. 37. Importantly, see Michel Foucault, History of Sexuality, Volume One: The Will to Knowledge, trans. Robert Hurley (London: Penguin Books, 1998). 
distinguished by scale, they are, in fact, imbricated: when biopolitics emerges, it draws on and indeed reworks discipline. It does this through a series of techniques, technologies, relays, and operations that, in Foucault's intriguing words, "make live."

Importantly, Foucault uses the term life-in relation to the concept of making live-to refer to the conditioning of biological capacities of the individual, and how these capacities are inextricable from the logics of governing. Foucault does not propose an ontology of life; rather, his concern is how biological life comes to be known and conditioned through various mechanisms and techniques-power-knowledge relations-that have taken life as an object. Life-living beings and the conduct of the living-becomes the arena where biopolitics manages and affirms particular forms of life (that is, bodies/selves) that have been produced through disciplinary mechanisms. Simultaneously, biopolitics comes to shape and modify forms of discipline that condition individual bodies. It draws on discipline by obliging individuals to enter themselves into the discourses of life so that they can then be advised how, through discipline, to lead a life, conduct themselves, and self-care. The ends of this form of biological governing concern the control, stabilizing, and improvement of life. In other words, to "make live" becomes a biopolitical imperative. Biopolitics affirms life through the imperative to make live and can thus be said to be a politics of affirmation. It orients the biological-living beings-towards life in a regulatory fashion. As such, this affirmation cannot be seen as neutral or liberatory. Instead, it is crucial that we recognize that life can only exist under certain conditions; it is contoured in particular ways; and some ways of living, not to mention forms of life, are valued above others.

Biomedicine works in line with these biopolitical goals to make live and is called on as an instrument of the governing of life; it fosters and regularizes certain forms and understandings of life. Therefore, biomedicine must be seen as regulatory, in that it is used to fulfill biopolitical imperatives to make live. One of the key ways that biomedicine achieves both the biopolitical and disciplinary organization of life is through affect. Affect is fostered, cultivated, and utilized within the biomedical arena, both in the clinical setting and in terms of individual engagements with biomedicine and the experience of illness. If, as Hemmings suggests, "affect manifests . . . as a central mechanism of social reproduction" within broader society, and, as Constantina Papoulias and Felicity Callard argue, affect is integral to the regulation of self, then affect can be seen to extend into all areas of biomedical rhetoric, practice, and individuals' encounters 
with the biomedical sphere. ${ }^{15}$ This is hauntingly articulated by Michael Taussig, who notes that "[i]t is within disease, with its terrifying phantoms of despair and hope that my body becomes ripe as little else for encoding that which society holds to be real." ${ }^{16}$

While multiple affects permeate medical encounters and condition individual feelings and responses to medical treatments and expertise, many critical scholars of biomedicine have identified hope as a dominant biomedical affect. ${ }^{17}$ Showing how hope pervades the biomedical arena in a number of ways, critical studies of the biomedicine and technoscience fields have analyzed the nuanced workings of hope, its deployment and operations at the individual and broader social levels: Mary-Jo Del Vecchio Good and colleagues have explored what they call the "political economy of hope" in oncology culture; Sarah Franklin has examined new reproductive technologies as "hope-technologies"; Tiago Moreira and Paolo Palladino have investigated the tensions and mutual parasitism of what they call the "regimes of hope and truth"; and Carlos Novas has built on the idea of a political economy of hope by applying it to the analysis of links among corporations, individuals, and the production of biovalue. ${ }^{18}$ Nik Brown's sustained attention to hope has drawn together multiple scholars working in this area of inquiry, and, further, extended understandings of how hope is mediated in biomedicine, specifically in terms of biomedical expectations. ${ }^{19}$

15. Hemmings, "Invoking Affect" (above, n. 11), p. 551; Papoulias and Callard, "Biology's Gift" (above, n. 9), p. 47.

16. Michael Taussig, "Reification and the Consciousness of the Patient," Social Science and Medicine 14 (1980): 3-13, quote on p. 4.

17. This is not to say that individuals do not experience other affective states in the face of illness (such as shame, anger, fear, or despair among others). These other affects are not fostered in the biomedical encounter-or in broader social articulations of disease and illness-in the ways that hope is.

18. M. J. Del Vecchio Good, B. J. Good, C. Schaffer, and S. E. Lind, "American Oncology and the Discourse of Hope," Culture, Medicine and Psychiatry 14:1 (1990): 59-79; Sarah Franklin, Embodied Progress: A Cultural Account of Assisted Conception (Abingdon, UK: Routledge, 1997); Tiago Moreira and Paolo Palladino, "Between Truth and Hope: On Parkinson's Disease, Neurotransplantation and the Production of the 'Self,'" History of the Human Sciences 18:3 (2005): 55-82; Carlos Novas, "The Political Economy of Hope: Patients' Organizations, Science and Biovalue," BioSocieties 1:3 (2006): 289-305.

19. Nik Brown, "Ordering Hope: Representations of Xenotransplantation—an Actant/ Actor Network Theory Account" (PhD diss., Lancaster University, 1998); "Hope Against Hype: Accountability in Biopasts, Presents and Futures," Science Studies 16:2 (2003): 3-21; "Shifting Tenses: Reconnecting Regimes of Truth and Hope," Configurations 13:3 (2005): 331-355; and "Shifting Tenses-From 'Regimes of Truth' to 'Regimes of Hope,'” SATSU Working Paper 30 (2006) (http://www.york.ac.uk/media/satsu/documents 
We take the investigation of hope in a different direction by examining it through the lens of Foucault's concept of the governing of life. Here, it is hope's organizing logic that must be explored, and the particular ways that conventions of hope secure the affirmation of life. Hope affirms the "truths" that undergird biomedicine. ${ }^{20}$ These might be understood as the following: techno-utopian transcendentalism, or the possibility of transcendence of corporeal limits and ends; progress to an undefined future; a salvationary ethics that directs toward optimism; and, more recently, optimization and enhancement of the human. ${ }^{21}$ By affirming these truths central to biomedicine, hope fosters life in particular ways. The biomedical affect of hope orients life toward these truths, and, in doing so, conditions conduct and produces biomedical subjects in line with the biopolitical imperative to "make live." Importantly, hope is conventionalized in particular ways that circumscribe what meanings or articulations of hope can exist, and how hope is deployed within biomedicine. Hope as biomedical affect disciplines individuals to affirm (a circumscribed) life-to experience their biomedical subjectivity through conventions of hope, and to hope as the way to fulfill the biopolitical imperative to live. Such disciplinary workings of hope within biomedicine, in turn, extend outward into the broader public arena and organize the masses at the biopolitical register.

In order to develop these claims further, the remainder of this essay focuses on hope in relation to cancer. Today, hope is ubiquitous in public cancer campaigns and services; cancer remains one of the clearest, most visible grounds of hope. The operations of hope are more observable in some cancers than others-for example, breast cancer compared to testicular cancer-but all cancers are, to some degree, managed and represented through the biomedical deployment of hope (and its relays and forays into the public

-papers/Brown-2006-shifting.pdf). See also Cheryl Mattingly's work on hope as a narrative phenomenology of practice for families with critically ill children in The Paradox of Hope: Journeys through a Clinical Borderland (Berkeley: University of California Press, 2010).

20. We use the term truth here in the Foucauldian sense, to refer to a regime comprised of types of discourse that an individual society "accepts and makes function as true"; see Michel Foucault, "Truth and Power," in Power/Knowledge: Selected Interviews and Other Writings, 1972-1977, trans. Colin Gordon, Leo Marshall, John Mepham, and Kate Soper, ed. Colin Gordon (New York: Pantheon Books, 1980), pp. 109-133, esp. p. 131.

21. Nikolas Rose, The Politics of Life Itself: Biomedicine, Power, and Subjectivity in the Twenty-first Century (Princeton, NJ: Princeton University Press, 2007); Adele E. Clarke, Laura Mamo, Jennifer Ruth Fosket, Jennifer R. Fishman, and Janet K. Shim, eds., Biomedicalization: Technoscience, Health, and Illness in the U.S. (Durham, NC: Duke University Press, 2010). 
realm). Hope is also inextricable from the "hard" technologies of biomedicine, such as clinical trials, treatment, experimental bodies, detection technologies, and genetic testing. But while attending to hope in relation to hard technologies is important, our purpose, here, is to consider the conventions of hope that are at work in the social environments of cancer treatment. First, however, it is necessary to address the shifts in the biomedical conventions of hope in the neoliberal era, building on the previous theoretical discussion of biopolitics, biomedicine, and affect. We turn now to survey cancer activism-specifically, breast cancer activism-as the terrain where biomedicine, and the biomedical conditioning of hope, can clearly be seen to articulate with neoliberal biopolitics.

\section{Neoliberal Biopolitics and Hope Weaponry}

Cancer has long been considered the target of war-that which war must be waged against-and hope has historically been fostered and deployed as a weapon to fight cancer. However, hope has become militantly optimistic, triumphant, individualistic, and highly commercialized in the biomedical and social sphere concentrated on cancer over the last several decades. This shift can roughly be said to coincide with the transition from the era of medicalization to that of biomedicialization: medicalization marked the extension of medical jurisdiction across areas of life not previously governed by medicine beginning in the early to mid-nineteenth century, while biomedicalization can be temporalized to the latter part of the twentieth century and is characterized by, among other things, the intensified reliance upon technology of the biomedical field and the extension of medicine from illness into the realm of health. ${ }^{22}$ The logic and conventions of hope that accompany these eras articulate varying biopolitical aims, employ distinct disciplinary techniques, and consequently produce divergent forms of biocitizenship. This term refers to the ways that citizenship, of the nation or of the social realm, has been increasingly framed and experienced in relation to the biological. For Nikolas Rose, biocitizenship marks "all those citizenship projects that have linked their conceptions of citizens to beliefs about the biological existence of human beings, as individuals, as men and women, as families and lineages, as communities, as populations and race, and as species." ${ }^{23}$ What we go on to show, however, is that biocitizenship does not always take nationalized form. Indeed, as Rose has argued, in the contemporary era, it

22. Clarke et al., Biomedicalization (above, n. 21).

23. Rose, The Politics of Life Itself (above, n. 21), p. 132. 
involves medical knowledge of one's "condition," a sense of belonging with others who share that condition, and a heightened sense of responsibility for one's own health, enabled through advancements in the biomedical sphere and technoscience.

Hope was first deployed in biocitizenship projects relating to cancer in the medicalization era of the late nineteenth and early twentieth centuries. During this time, a generalized silence accompanied the disease, and there was an overriding popular belief that a cancer diagnosis inevitably resulted in death. Despite high incidence and mortality rates, cancer received little public attention. To combat these issues and work toward the goal of the promotion of life, public education efforts and a series of social-control programs were initiated. These projects largely endeavored to "fight cancer with publicity" and combat the fear and silence surrounding it with hope. The centrality of hope in these biocitizenship projects is most clearly seen in the American Society for the Control of Cancer's (the ASCC, which became the American Cancer Society [ACS]) formal adoption of the "Sword of Hope" symbol in 1928. The sword was used to promote the idea that vigilant detection, knowledge, and education would enable individuals to hope that they would not succumb to cancer, but could instead battle it and thus make themselves live. ${ }^{24}$ Hope, in this era, was beginning to be militarized; it was considered the battle cry to wage war on cancer, and the sword rallied hope in order to encourage individuals to take responsibility for their own health and that of their families, and to discipline themselves with the aim of achieving national protection. ${ }^{25}$ This goal required a collective front of biocitizenship, formed through the disciplinary techniques of individual awareness, surveillance, and acquiescence to medical oversight. The affective work of hope within biomedicine at this time operated within the biopolitical governing strategies that structured the era of medicalization: illness was to be controlled, the health of the population was to be regularized in line with normative standards, and collective risk was

24. Barron H. Lerner, The Breast Cancer Wars: Hope Fear, and the Pursuit of a Cure in Twentieth-Century America (New York: Oxford University Press, 2003).

25. Integral to this rising public visibility of cancer was the formation of the Women's Field Army (WFA). Established in 1936 and initiated by the ASCC, the WFA adopted the Sword of Hope as its moniker and aimed to collectively organize "trench warfare with a vengeance against a ruthless killer" (qtd. in ibid., p. 43). This legion of volunteers was organized vertically, with an officer's corps and foot volunteers; enlisted women wore khaki uniforms with insignias of rank and achievement. Medals honored length of service, and an array of pins and buttons depicting the sword were utilized by the WFA and supporters to mark their membership and commitment to the cause. By 1943, the army numbered between 350,000 and 700,000 (ibid., p. 44). 
to be abated. Thus, the population was administered as a social enterprise. Within this logic, cancer was seen as a disease that could be controlled by knowing its symptoms and anticipating its signs, and thus both hope and cancer's curability relied upon early detection once the disease had appeared. This possibility, however, could only be mobilized through the militancy of citizens over their own bodies and those of their families; to do otherwise meant that one failed as a citizen. The Sword of Hope was a call to arms in this enterprise, where the conquest of cancer was framed as a civic duty, a matter of honor, and a heroic endeavor that required the vigilance of the entire population. The welfare and care of the population was the focus, beliefs of the "social good" prevailed, and life became a responsibility and national duty. ${ }^{26}$

In contradistinction to this earlier welfare-oriented deployment of hope, the latter half of the twentieth century, particularly the neoliberal era, has seen a modification and transformation of hope logics in biomedicine. Biomedicine operates differently in the era of what Melinda Cooper calls "neoliberal biopolitics," 27 which refers to a range of social, political, and economic rationalities, programs, directives, and policies that work across multiple scales-local, regional, national, global. For our purposes, neoliberal biopolitics can be characterized most broadly by a declining welfare imperative and the increasing absence of the idea of society or of a collective social good; a heightened individualizing of the administration and management of life; a reworking of life beyond its perceived limits (in contradistinction to the earlier period's regularizing of life and collectivizing of risk). Massive investment in the life sciences and biotechnologies from the 1970s onward has effectively led to a political economy of life that speculates on life and its possibilities, in addition to the administration of life toward a certain telos. ${ }^{28}$

26. This militant hope circulated in popular culture, through mediums like posters that exhorted citizens to vanquish cancer by learning about it, looking for symptoms, and pursuing early diagnosis and treatment. Many of these posters highlight how the ACS addressed the personal, specifically the family, as the realm where cancer awareness and vigilance needed to be cultivated. Through personal responsibility, cancer could be detected and attacked; cancer is framed here as that which could be met with retaliatory action. It is the family that serves as the space where a collective front of biocitizenship can be imagined; for while various medico-technical advancements were unfolding during this time period, national protection and the strength of national health relied upon individual and familial participation in these efforts.

27. Melinda Cooper, Life as Surplus: Biotechnology and Capitalism in the Neoliberal Era (Seattle: University of Washington Press, 2008), p. 8.

28. Here, the telos would be optimization; see ibid., and Rose, The Politics of Life Itself (above, n. 21). 
Biomedicine operates in line with these shifts. In the contemporary period of biomedicalization, biomedicine reflects and conditions the key characteristics of neoliberal-biopolitical existence in the United States. Biomedicine increasingly customizes, rather than normalizes, the body; it has extended its terrain from illness to the more all-encompassing and pervasive regime of "health"; and, through the genetic and molecular framing of life, it has provided the opportunity to further individualize life and create alternative forms of biocitizenry that are focused on militant self-care and preemptive practices, and that move away from an over-arching sense of national belonging and protection. Attendant to these shifts in biomedicine under neoliberal biopolitics, hope is increasingly corporatized and commodified. There is an intensification of the moral obligation to hope; hope is now seen not as a social and collective expression of national belonging and welfare, but instead as something potentially embodied in one's own biological material and facilitated by biotech advancements and corporations. Hope remains central to governing, but it now involves an intensification of militarization, a heightened individual triumphalism and insistent optimism, and a relentless effort to optimize life, to make (individuals) live (more).

The Walther P-22 "Hope" edition handgun captures the significant neoliberal shifts of hope in biomedicine as they relate to cancer and the production of biocitizenry. The figure of a "hope gun" paradoxically mobilizes the new optimization of life at the same moment that it serves as a technology of killing: the gun's specter of death is absurdly drafted in the service of the cure for cancer. Discount Gun Sales, a US gun-manufacturing company, recently produced a limited number of these customized pistols, which sported a pink Duracoat finish. They were introduced during Breast Cancer Awareness Month in 2011 with the original intention of donating a portion of the gun-sale proceeds to the Susan G. Komen Foundation for breast cancer research. ${ }^{29}$ The gun was so successful that, in 2012, the company initiated a second production line. While we do not mean to suggest that the hope gun now serves as the ultimate public image of cancer or the paradigmatic symbol of hope under neoliberal biopolitics, its existence does represent the extent to which the governing of life has changed. That this gun could even be conceived, let alone be commercially successful, indicates

29. This information was available at the site "Open Letter Concerning the Susan G. Komen Foundation," http://www.discountgunsales.com/SGKF.pdf. All reference to the gun has since been removed from the Discount Gun Sales website; however, an archived version of the letter is at http://big.assets.huffingtonpost.com/SGKF.pdf. 
the massive transformations in the ways that neoliberal governance "makes live," and, specifically, how cancer awareness and activism have been militarized.

Breast cancer activism has witnessed the corporatization and commercialization of hope weaponry. Breast cancer currently receives more coverage than any other, and hope permeates almost all rhetoric and practices that surround the disease. ${ }^{30}$ Breast cancer is the disease that inspires, demands, the most hope, and such hyper-visible hope has been largely achieved through the commercialization of breast cancer activism and the blurring of education, activism, and marketing. For example, the pervasive color known as "breast cancer pink" allows for the expression of awareness and support for breast cancer activism through pink-branding ("pinkwashing") and consumerism. Hope is now key to making breast and other cancers palatable through the conventions of the commodity. A "hope edition" breast-cancer-pink handgun is merely one product in a wide array of commodities within cancer popular culture and activism wherein hope functions as an affective currencyhope is bought and sold. By buying the breast cancer handgun (or any other kind of hope paraphernalia), one participates in a market of/for hope: one buys into a system of optimism and consumer identification-an economy sponsored by corporate bodies-to show support for the cause. In this context of consumerism, cancer continues to be met with war, and breast cancer activism has territorialized that battleground as the disease that demands the most militarization of hope. However, the incitement to participate in breast cancer activism has become so militantly consumeristic and moralized that the purchase of an instrument of killing-an anti-breast cancer hope gun-can be justified and even celebrated. While the gun is an extreme example, it is not far afield from one of the dominant figures in contemporary US breast cancer culture: the "pink warrior," a highly individualized and triumphalist symbol of resistance to breast cancer. This militant pink hero rallies public hope and optimism to combat the threat of cancer in/through commodified images and ideas of a certain form of feminism-universalized sisterhood, self-empowerment, girl power, and so forth—and through spectacles of hope, such as mass rallies.

30. For a comprehensive account of breast cancer activism and politics, see Nadine Ehlers and Shiloh Krupar, editors of "The Body in Breast Cancer" special issue in Social Semiotics 22:1 (2012); Ehlers, "Risking 'Safety': Breast Cancer, Prognosis, and the Strategic Enterprise of Life," The Journal of Medical Humanities (2014). DOI 10.1007/ s10912-014-9288-2 (Online First).; and Barbara Ehrenreich, "Welcome to Cancerland: A Mammogram Leads to a Cult of Pink Kitsch," Harper's, November 2001, pp. 43-53. 
This militant hope in breast cancer culture dovetails with a more general hyper-vigilant approach to the individual body in the neoliberal era of biomedicine. Advancements in biotechnology-the "march of progress" to current forms of genetic testing-have initiated new understandings of the body and practices of self-care (forms of individual discipline) that emphasize both individual genetic risk and health as a continuum. Departing significantly from the earlier era's curative model of disease, the paradigm has now shifted from cancer's curability after evidence of disease to a new form of lifethe search for "the cure" - that involves endless detection and prediagnostic subjection: there is no end to this active search for potential disease, embodied risk, and the cure. Life, then, exists within a "pre-vivor" to "survivor" loop, and health has become an endless and hyper-vigilant individual enterprise. Breast cancer surveillance, in particular, through the historical mounting of biotechnologies, from the pap smear in the 1940s, to the mammogram in the 1960s, and genetic testing in the 1980s, has become a speculative and endless quest for the cure, to the extent that militant medical disciplining of the body through disease surveillance now traverses all stages of life. For example, there have been proposals to remove the breast buds of girl children who test positive for the BRCA1/BRCA2 breast cancer genes. ${ }^{31}$ The cure for breast cancer is, therefore, biomedically illusive, in that it defers any possibility for the "end" of cancer by enfolding persons without symptoms, along with unwanted and unknown futures, into the present in the name of hyper-vigilant cancer preemption. The hope gun is the penultimate fetish of this militant affirmation of life through constant preemptive action.

Biocitizenship is thus changing in the era of neoliberal biopolitics: in the absence of collectivizing incentives of welfare notions of health, we are now witnessing the emergence of new forms of citizenship where individuals increasingly think of themselves in relation to their biological, genetic, or corporeal status and discipline themselves accordingly. ${ }^{32}$ However, if life is now understood as that which can be endlessly enhanced, optimized, customized, commodified, and biologized, then hope is re-presented and used in our

31. F. M. Hodges, J. S. Svoboda, and R. S. Van Howe, "Prophylactic Interventions on Children: Balancing Human Rights with Public Health," Journal of Medical Ethics 28:1 (2002): 10-16, esp. p. 11.

32. In this operation, groups of individuals are claiming "belonging" to a particular disease or biological classification, representing what Paul Rabinow has called "biosociality"; see Rabinow, "Artificiality and Enlightenment: From Sociobiology to Biosociality," in Incorporations, ed. Jonathan Crary and Sanford Kwinter (New York: Zone Books, 1992), pp. 234-252. 
current era to govern subjects according to these understandings. Hope is now articulated (and comes to be embodied) as the refusal to be limited to biological capacity; the way to speculate on one's own life, and life in general; the relentless optimism and demand for more (individual) life; the hyper-vigilance required of disease preemption; and the militant affirmation of the endless productivity and potential of biotechnology and biomedical advancements. Hope logics are structural to biomedical political economies and neoliberal biopolitics, and they organize how individuals come to incorporate biomedical truths and neoliberal rationalities in their daily lives. In incorporating these truths, individuals are not only what Foucault would call the inert or consenting targets of biomedical power/knowledge and governance, but "they are always also the elements of its articulation." ${ }^{33}$ In the next section, we turn to the way that neoliberal conventions of hope are enacted within clinical settings related to cancer. In such settings and attendant biomedical encounters, hope can be seen to govern the subject with cancer. We first consider how such governing via hope operates in what we call "infrastructures of care"-institutional arrangements and their aesthetics of care. Second, we consider how this governing through hope operates as a "bioethics of faith," where both the possibility for hope and the ethical relationship of self-to-self and biomedicineto-patient are structured as faith.

\section{Care and Faith: Hope in the Biomedical Encounter}

It is difficult to imagine any form of cancer care not predicated on hope. The sustained marriage between care and hope constitutes the very essence of countless cancer-treatment spaces and practices that regard fostering hope to be integral to providing care. The pursuit of hope as an operation of care is well-established and continues to set the stage for biomedical encounters: people interface with biomedicine in/through care services that aver hope. In the neoliberal era, hope is intensively fostered, and the subject governed, through architectures of care that instrumentalize interior design and customize medical services in the cause of hope-in other words, the increased efficiency and corporatization of care, combined with hope thematics. Numerous hospitals, medical centers, and cancertreatment hubs employ hope in their titles, such as Hope City in Los Angeles, one of only forty National Cancer Institute-designated comprehensive cancer-treatment centers. Hope medical-care titles

33. Michel Foucault, "Two Lectures," in Power/Knowledge (above, n. 20), pp. 78-108, quote on p. 98. 
also have a global presence, demonstrated by the numerous North American examples beyond the borders of the United States, such as the Breast Cancer Center of Hope in Manitoba, Canada, and the Oasis of Hope Cancer Hospital in Tijuana, Mexico. Many of these treatment centers strive to integrate cancer-care services-blood tests, scans, chemotherapy sessions, and other support provisions-under one roof. Hope is generated through the efficiencies of a coordinated, consolidated, and comprehensive infrastructure of care. The integration of different offices and services reduces patient travel and allows for enhanced customization of care. Treatment centers organize doctors and medical service professionals into "care teams" that collaborate and customize procedures according to each patient's needs. The patient is thus treated as an individual fulcrum of hope that can be leveraged by a care team, well-organized services, and effective architecture.

Beyond teamwork tailored to each patient and the fostering of hope through architectural efficiencies, cancer-care centers also seek to cultivate hope through spatial arrangements and decor. Treatment centers increasingly attempt to embody hope-hope as inspirational, calm, compassionate, and optimistic care-in their very architectural designs and interiors. For example, the Mission Hope Cancer Center in Santa Maria, California, which opened in late April 2012, offers "comprehensive compassionate cancer care" within one three-story, 44,000-square-foot building, featuring a Mediterraneanstyle architectural exterior with natural landscaping and vistas of the surrounding valley. ${ }^{34}$ The interior design includes external windows that pool warm, natural light; spacious seating rooms in earth tones; large ceiling portals that brighten enclosed rooms with backlit images of blue sky; and enlarged nature photographs that serve as kiosk screens, room dividers, and window shades and that express light as natural shading. Surf photography dons many of the walls, to exude color and motivational flourishes; expansive windows overlooking the Santa Maria Valley serve as backdrop to the administration of chemotherapy on the third floor; and patients undergoing various scans and procedures can gaze on vividly back-lit, majestic landscape images that have been incorporated in the ceilings. Such hope-theming, particularly the enlarged nature transparencies, create a calming and contemplative "aquarium-bowl" effect; one potentially feels better about one's disease or illness on viewing inspirational nature at every interface within the medical establish-

34. See the Mission Hope Cancer Center website at http://www.missionhope cancercenter.com/index.html. 
ment. Mission Hope Cancer Center's "nature-sanctuary" interior design conditions patients to admire nature, feel comfortable, be positive, and pursue treatment of oneself as part of the larger flourishing of life.

A second example, the University of Arkansas for Medical Sciences (UAMS) Winthrop P. Rockefeller Cancer Institute in Little Rock debuted, in 2010, a twelve-story, 300,000-square-foot expansion for cancer research, treatment, and outreach. The design of the entire building was carefully considered as a means to inspire the hope of patients and their families. ${ }^{35}$ The interior holds numerous hopethemed environmental attributes: wall-displayed affirmations like "While there's life, there's hope," live piano playing, and an atrium housing a garden and the "Seed of Hope" sculpture-the hallmark of the entire building. ${ }^{36}$ Carved from white-pearl Turkish marble and standing two-feet high, this sculpture of a large seed serves as a dedicated monumental receptacle for Seed of Hope tokens. ${ }^{37}$ Such tokens, which feature the logo of the institute on one side and an impression of the interior of a seed on the other, are presented to patients on the final day of their active cancer treatment. Each patient is given two seed coins: one token is placed in the sculpture to commemorate survivorship, and the other is taken home by the patient to keep or to gift to another person as a symbol of hope. ${ }^{38} \mathrm{In}$ this scenario, hope is symbolically minted in monetary-coin form and pressed into the service of an expansive, contemplative, timeless, and copyrighted landscape of cancer care, extending from the sculpture itself to the larger building surrounding the atrium and sculpture and to the pockets and homes of cancer patients and their relations. Such an affective economy encourages the cultural acceptance of cancer through the visually encouraging accumulation of hope; it also primes individuals to accept, internalize, and advertise corporatized forms of care.

The contemporary corporatization of cancer care-and the contradictions that attend it-can be further explored through examination of the ACS-administered Hope Lodge ${ }^{\circledR}$ network. Various Hope

35. "UAMS Expands Cancer Treatment and Research Facilities." http://www .magnoliareporter.com/news_and_business/regional_news/article_d58c680a-9c30 -11df-8230-001cc4c03286.html?success.

36. See the UAMS Winthrop P. Rockefeller Cancer Institute website at http://www.seeds -of-hope.com/.

37. "Artist Creates 'Hope' at Cancer Institute," http://ualr.edu/www/2010/08/03/ualr -artist-creates-seeds-of-hope-at-new-cancer-institute/.

38. See http://www.seed-of-hope.com/about-the-seeds-of-hope/. 
Lodges have been built in urban centers across the United States. Each offers cancer patients and their caregivers invaluable free, temporary lodging when specialized cancer treatments are unavailable near their homes. Hope Lodges also offer many practical services and infrastructures essential to everyday life in order to reduce the financial and emotional burdens of cancer treatment: guest rooms and private baths, common kitchens, computer work-stations, a library with educational material on hand, local transportation to and from treatment, and additional communal opportunities, including yoga, Tai Chi, and shared meals. ${ }^{39}$ Such care employs the architecture and interior environment to nurture hope, home-like comfort, private retreat, and community connection. With thirty-one locations currently bearing the official trademarked name, Hope Lodges serve and simulate community welfare-especially critical in the context of the US market-driven healthcare "system," which provides few guarantees and limited custody of those facing illness and disease. The provision of this hope network presents corporations an opportunity to articulate hope through corporate benevolence, such as AstraZeneca's donation of $\$ 7$ million for the founding of the Hope Lodge in Boston in 2006, now accordingly named the "AstraZeneca Hope Lodge Center." ${ }^{40}$ Similar to what critics have called "greenwashing," corporate sponsorship can strategically function as "carewashing"-drawing attention to corporate social responsibility in one corner, while irresponsible and harmful practices continue elsewhere. ${ }^{41}$ Rather than contributing to the marginalized research on the environmental causes of cancer, which could potentially implicate corporations like AstraZeneca and their predecessor companies, hopeful architectures and networks of care could be seen to "band-aid" over what some critics refer to as the "cancer-industrial complex" 42 or "U.S. Biomedical TechnoService Complex Inc.," ${ }^{43}$ obfuscating potential hazards and harms that commence or continue

39. See the ACS's Hope Lodge website at http://main.acsevents.org/site/PageServer ?pagename $=$ ACSHL_homepage.

40. "American Cancer Society Raises \$22 Million for Hope Lodge Boston Construction." http://www.cancer.org/myacs/NewEngland/AreaHighlights/american-cancer-society -raises-22-million-for-hope-lodge-boston-construction.

41. On "greenwashing," see Cindi Katz, "Whose Nature, Whose Culture? Private Productions of Space and the 'Preservation' of Nature," in Remaking Reality: Nature at the Millenium, ed. Bruce Braun and Noel Castree (London: Routledge, 1998), pp. 45-62; and Shiloh Krupar, Hot Spotter's Report: Military Fables of Toxic Waste (Minneapolis: University of Minnesota Press, 2013).

42. Ehrenreich, "Welcome to Cancerland" (above, n. 30).

43. Clarke et al., Biomedicalization (above, n. 21). 
under the banner of corporate benevolence and the intensified reliance upon corporate charity as the arena and conduit for medical care in neoliberal times.

Beyond being pursued and fostered in practices of care, hope also operates in a second sense in the biomedical arena, as a form of faith. US oncology, most specifically, is permeated by a discourse of hope as faith in biomedicine, in the self, and in the affirmation of life. ${ }^{44}$ Such hope refuses the limits of life and calls on subjects to become active participants that instrumentalize the future, discipline themselves to be hopeful, and maintain faith in biomedical progress. While historically, Western science and medicine can be seen to supersede religious truth and salvation with a telos of progress, current techno-utopian orientations toward biotechnologies, attendant to the shift within biomedicine from control to customization and participation, have made hope a bioethics of faith-a never-ending salvationary enterprise wherein subjects internalize the pursuit of hope and relentlessly seek to marshal faith in the endless affirmation of life through diverse means.

This bioethics of faith is most clearly seen in oncology, where a tension often exists between disclosure-a historically won patients' "right to know" - and the practical need to maintain patient cooperation with treatment regimes and what has been called the "principle of respect for hope." 45 Although hope has been criticized as providing justification for paternalism, the withholding of information, and other harms within the biomedical realm, the full disclosure of diagnosis can also be interpreted as medically inappropriate if it jeopardizes hope. Prognostic ambiguity and uncertainty, then, are the grounds on which disclosing and withholding of information are negotiated in the name of securing and managing hope. A dedicated interest in fostering hope can subvert the medical imperative of full disclosure (at the core of medical ethics), particularly when prognoses are bleak, with "facts as the killing fields." ${ }^{46}$ When truth is not a productive means to manage patients, oncology enlists hope as an active therapeutic tool that orients patients to the future, affirms life, and rallies faith in the pursuit of always-more medical possibilities. Some even consider the oncologist's vocation

44. Del Vecchio Good et al., "American Oncology and the Discourse of Hope" (above, n. 18).

45. Eric Kadish and Stephen G. Post, "Oncology and Hope," Journal of Clinical Oncology 13:7 (1995): 1817-1822, quote on p. 1817.

46. Brown, "Shifting Tenses: Reconnecting Regimes of Truth and Hope" (above, n. 19), p. 338; see also Kadish and Post, "Oncology and Hope" (above, n. 45), p. 1818. 
to be that of instilling hope, of balancing the obligation to be honest with "an equally important duty to cultivate hope." ${ }^{47}$ Hope is understood to be transformative, potent, even capable of influencing the biological course of cancer; patients, therefore, have a right to it. This right to hope is intimately tied to US-based notions of effective personhood and faith in the ability of individuals to shape life and corporeal functions through the power of will. ${ }^{48}$

This "allegiance to the efficacy of personal volition and the capacity of the self to mobilize a 'desire for life,' a 'will to live' and a 'fighting spirit'" is evident in the development and use of "hope scales" since the 1970s. ${ }^{49}$ These instruments of psychometric measurement use affect for intense scrutiny, surveillance, and objectification; more specifically, they provide a means of assessing how much hope you have, through the establishment and deployment of norms of acceptable levels of hope. The hope scales involve the administration of a carefully crafted series of questions that are then scored. Several scales are currently in existence, each exhibiting different nuances and backed by an expansive research network dedicated to the quantitative study of the hopeful properties of cancer patients..$^{50}$ As a whole, these hope diagnostics bifurcate psyche and soma, compelling subjects to monitor and regulate the psyche in order to heal the body. They substantiate hope as central to extended survival, harmonize patients with the aspirations of treatment programs, and, by splitting the psyche and soma, foster belief in the responsibility of the individual to gather "the necessary affective resources in overcoming personalized pathology." ${ }^{51}$ Hope is essentially pathologized, and subjects are held accountable for hope's absence and disciplined to actively cultivate it.

Another way that individuals are called on to hope as a form of faith is through virtually participating in games that are designed to impart knowledge to patient-players about disease and treatments, rehearse medical protocols, and cultivate faith in self-efficacy. The nonprofit organization HopeLab, which engages in consumercentered product development "to enhance the physical health and psychological well-being of young people with chronic diseases,"

47. Del Vecchio Good et al., "American Oncology and the Discourse of Hope" (above, n. 18), p. 75.

48. Ibid.

49. Brown, "Shifting Tenses-From 'Regimes of Truth' to 'Regimes of Hope'" (above, n. 19), p. 12.

50. Ibid., p. 11.

51. Ibid. 
brought together video-game designers, health psychologists, and cancer researchers to design a game for young people with cancer. ${ }^{52}$ The intention was to create and market a game that equipped patient-players with motivational and transformative affective experiences in order to practice vigilant self-care, virtually battling their disease by adhering to the protocols of prescribed medications, timely symptom reporting, and side-effect management. The result was a Microsoft Windows-based, third-person shooter gameRe-mission ${ }^{\mathrm{TM}}$-released in 2006 with twenty-plus levels of gameplay. Re-mission ${ }^{\mathrm{TM}}$ invites players to immerse themselves within the complex, microscopic world of cancer-ridden bodies in an epic battle against cancer, wherein one's weapons are upgraded and more life is achieved if virtual vigilance is maintained. ${ }^{53}$ In the game, patientplayers pilot a sassy nanobot named Roxxi through the cellular level of teenaged cancer patients to investigate symptoms, destroy cancer cells, stop metastases, and activate patients into "chemo compliance." ${ }^{54}$ Players live out the contingencies of treatment in the game's virtual organic proving grounds. For example, if a patient skips chemotherapy doses, then Roxxi's chemo-concentrating blaster misfires every third shot and the cancer cells survive and become drug resistant. Considered a flagship for the health-gaming movement, with reportedly more than 185,000 copies distributed free of charge across eighty-one countries, the game has undergone controlled trials to measure its impact on patient behavior, and, based on these results, is said to have stimulated an increase in positive cancer-related attitudes by "transforming mundane medication into bullets to kill the enemy cells, and by changing the humdrum routine of swallowing pills into a heroic act." ${ }^{55}$ Essentially, subjects internalize the biomedical pursuit of hope through the game's rehearsal of highly militaristic and individualistic self-care. By playing the game, subjects rally faith in biomedicine and, through technoutopian transcendence, affirm life, the power of the self, and martial

52. R. Tate, J. Haritatos, and S. Cole, "HopeLab's Approach to Re-Mission," International Journal of Learning and Media 1:1 (2009): 29-35, quote on p. 29.

53. The game's advertising declares that "[a]n epic battle rages deep in the realms of the human body. Colonies of microscopic cancer cells are replicating, attacking, and damaging healthy organs of young people from all across the United States. Enter Roxxi, your courageous and fully-armed nanobot and medicine's mightiest warrior." See http://www.hopelab.org/innovative-solutions/re-mission ${ }^{\mathrm{TM}} /$.

54. "Re-Mission 2 Video Game Now in Development." http://www.nanopaprika.eu /profiles/blogs/remission-2-video-game-now-in.

55. Kate Metropolis, "Steve Cole," Health Games Research. http://www.health gamesresearch.org/our-publications/featured-colleagues/steve-cole. 
values. Re-mission ${ }^{\mathrm{TM}}$ activates a powerful exercise of militarized faith in self-efficacy, and in doing so both secures hope and the biopolitical optimization (of a certain form) of living.

Spiritual guidance around cancer treatment is another area where hope as faith proliferates, as a joint venture of medical and religious communities. The integration of various spiritual diagnostics and services in the formal clinical process of treatment-what is often referred to as a holistic approach-increasingly dominates the field of cancer care. Regardless of the faith-based religious content at work in different cases, the biomedical imperative in oncology to foster hope and affirm life interestingly dovetails with many religious imperatives. For example, research has been underway on the hypothesis that individuals with spiritual struggle have greater mortality, and the reverse, that spirituality heals and faith is "medicine's neglected spirit." 56 While biomedicine could be said to use religion to generate hope, the reverse could also be asserted. Religious communities have been engaged in biomedicine throughout the history of healthcare in the United States. Religiously affiliated hospitals and treatment centers, for instance, have a longstanding formal presence, especially Christian-oriented care and charity. What is new, however, are the explicit promotional claims and niche businesses of customized/individualized spiritual medical care that are taking place within the competitive healthcare market. The Cancer Treatment Centers of America (CTCA) emblematizes this significant trend, advertising their provision of "mind-body medicine," spiritual guidance, and a "mother standard of care," along with cuttingedge biotechnologies and treatment programs. ${ }^{57}$ CTCA's "care that $^{\text {CT }}$ never quits" slogan asserts interminable care as the means to endless hope, and their highly visible marketing strategy emphasizes the integration of medical faith and spiritual custodianship-that spiritual faith is vital to battling cancer. ${ }^{58}$

A related though less readily apparent facet of the CTCA is its Our Journey of Hope ${ }^{\circledR}$ spiritual-support program, which advocates the

56. See Onoyemi Benedict, "Medicine's Neglected Spirit: The Positive Therapeutic Effect of Spirituality," on the CTCA's Our Journey of Hope® website, http://www .ourjourneyofhope.com/resources/articles/medicine-s-neglected-spirit-the-positive -therapeutic-effect-of-spiritualit.

57. The phrase "mother standard of care" seems to imply the ultimate standard of care that, rather than being simply custodial, is representative of love.

58. See, for instance, Robert L. Dupont, "The Healing Power of Faith: Science Explores Medicine's Last Great Frontier," on the CTCA's Our Journey of Hope® website, http:// www.ourjourneyofhope.com/resources/articles. 
communion of faith in care and healing with faith in God. ${ }^{59}$ This salvationary enterprise, which portends to establish relations between medical and spiritual communities ("when religion and medicine embrace"), not only indicates a competitive strategy within the neoliberal marketplace of healthcare-the niche of serving spiritual hope and guidance-but also structures individual relations with biomedicine in such a way that patients have an opportunity to be born again through biomedical encounters, to heal themselves through relations with God and renewed Christian faith and optimism. ${ }^{60}$ This extends individual self-care beyond the biological limits of the human to vigilance by God. Religion compounds the biomedical affirmation of life to proliferate hope: if biomedical faith is hope in biomedicine to affirm biological life, then its combination with faith in God expands hope's telos beyond life and death. This expansion of affirmation beyond life and death, however, means that individuals now bear intensified moral and social responsibility to get healthy through God, matched with biomedical advancements. An article posted in the resources section of the CTCA's Our Journey of Hope ${ }^{\circledR}$ website, "Don't Waste Your Cancer," implores readers to see their illnesses as a productive enterprise of faith: "You will waste your cancer if you do not believe it is designed for you by God. .. . You will waste your cancer if you believe it is a curse and not a gift.... You will waste your cancer if you seek comfort from your odds rather than from God.... You will waste your cancer if you grieve as those who have no hope." ${ }^{61}$ To do otherwise- "to waste your cancer"-is not mere failure, with respect to the biopolitical imperative to enhance and optimize life; it is the fault of individuals - and individuals are deserving of death-for not attending to spiritual care, for not having faith in God, for not allowing cancer to teach them how to be endlessly hopeful. The title of another CTCA-posted article alludes to this final judgment and the anathema that is death under the evangelical biomedical banner of endless hope: "Atheist Doctors More Likely to Hasten Death." 62

\section{Ibid.}

60. Ibid.

61. The CTCA's Our Journey of Hope® website, “Don't Waste Your Cancer," February 15, 2006. http://ojoh.hopenavigators.com/resources/articles/don-t-waste-your-cancer.

62. The CTCA's Our Journey of Hope® website, "Atheist Doctors More Likely to Hasten Death: Survey Finds Religious Beliefs Could Affect Care of Terminally Ill Patients." http://www.ourjourneyofhope.com/resources/articles/atheist-doctors-more-likely-to -hasten-death. 


\section{Hoping for Other Things: Alternative Hope Tactics}

As evidenced through the operations of care and faith, the affect of hope has a governing function in biomedicine. It is deployed in ways that support the biopolitical focus on enhancing the life of the population and increasingly structures the way that individuals are governed. This claim is clearly substantiated through the example of cancer culture, wherein hope directs an optimistic orientation to the future and to life often predicated on militant organization and consumption. Hope is promoted and pursued and comes to function as a regulatory affect, disciplining social engagements with and individual responses to cancer: it affirms life, and this affirming relentlessly circumscribes the kind of life that can be lived and the forms of hope that are socially celebrated and endorsed.

This affirmation of life through hope is an intervening into life, a promoting of life. Biomedicine, here, as Foucault claims, clearly operates as "a political intervention-technique with specific powereffects." ${ }^{63}$ However, not all forms of life are fostered equally. In this essay, we have not addressed the unequal enhancement of life under biopolitics and the overtly violent machinations of neoliberalism. There are clear disparities in the possibilities for health and life produced through the structural and ideological workings of race, class, sexuality, gender, and other geopolitical and geographical specificities. Such inequities in the ability to pursue life or to have one's life affirmed have been theorized in a range of ways-as social death, premature death, slow death, or what Foucault referred to as "let die." ${ }^{64}$ According to him, "letting die" is integral to the biopolitical imperative to "make live" and entails various operations of abandonment, negligence, and oversight: "In modernity, making live and letting die become logical correlates." ${ }^{65}$ Due to the vicissitudes of resource allocation and social stratification, some are made to live (more) at the expense of others. ${ }^{66}$ The centrality of "letting die" to

63. Foucault, "Lecture Eleven" (above, n. 12), p. 252.

64. For more on "social death," see Orlando Patterson, Slavery and Social Death: A Comparative Study (Cambridge, MA: Harvard University Press, 1982); for a discussion of "premature death," see Ruth Wilson Gilmore, Golden Gulag: Prisons, Surplus, Crisis, and Opposition in Globalizing California (Berkeley: University of California Press, 2007); and for more on "slow death," see Lauren Berlant, "Slow Death (Sovereignty, Obesity, Lateral Agency)," Critical Inquiry 33:4 (2007): 754-780.

65. Stuart J. Murray, "Thanatopolitics: On the Use of Death for Mobilizing Political Life," Polygraph: An International Journal of Politics and Culture 18 (2006): 191-215, quote on p. 197.

66. Stuart J. Murray, "Care of the Self: Biotechnology, Reproduction, and the Good 
"making live" highlights that death is always inside life; however, this death is made invisible. ${ }^{67}$

The biomedical affect of hope plays a specific role in this general obfuscating of death in two clear ways. First, in cancer culture, hope works to obscure the political character of the disease-for example, in the lack of attention directed toward cancer-causing toxicity and pollution and differential access to healthy environments, food choices, and the biomedical embrace. In this regard, there are "hope haves" and "hope have-nots." Second, the deployment of hope eclipses the realities of the disease by refusing a space to address fear, precarity, uncertainty, and pain; for Sarah Lochlann Jain, "that politics and suffering is more easily black-boxed behind chipper wrapping paper." ${ }^{\prime 68}$ Moreover, if the biomedical affect of hope is constructed as always-already positive and future-oriented, then the disease can only be approached as something to be overcome, surmounted, or vanquished. This kind of hope is what is called on as the acceptable and indeed the only possible response to cancer diagnosis and treatment because it is this kind of hope that facilitates the triumphant march onwards-to more life. The problem here is obviously not hope in and of itself, but the particular conventions of hope that are normalized within, and operate as, biopolitical governance, and the reality that only certain kinds of life can be affirmed and hoped for-positive, ongoing life. The biopolitical affirmation of life, conditioned through the conventions of hope that we have analyzed, leaves little room to meditate on death or the collateral damage of living under the shadow of imminent death, and it renders invisible those individuals who can be said to "live out" the let-die component of biopolitics. The vulnerability and often "let-die reality" of the subject with cancer does not, cannot, register. These are the other lives, ones that fail to achieve "life" as it is known in dominant knowledge systems and/or those lives abandoned, truncated, or elided in the social sphere. Hope is therefore not inherently "good," nor is the affirmation of life; rather, hope, as it operates in the biomedical arena and broader social sphere in relation to cancer most specifically, has an ominous quality, with pernicious effects. Hope obscures the regulatory and political-economic nature of the affirmation of life and circumscribes social responsibility and

Life," Philosophy, Ethics, and Humanities in Medicine 2:6 (2007). http://www.peh-med .com/content $/ 2 / 1 / 6$.

67. Ehlers, "Risking Safety" (above, n. 30).

68. Sarah Lochlann Jain, "Survival Odds: Mortality in Corporate Time," Current Anthropology 52:3 (2011): 45-55, quote on p. 46 (emphasis in original). 
ethics; it places the onus on the individual as an agent for life, and fosters a militantly optimistic approach to that life.

In the context of these conventions of hope, precious few alternative articulations or tactics of hope and life in relation to cancer exist. Such alternative imaginings are generally overshadowed, or risk being deemed pathological, due to their failure to assemble and reflect acceptable responses to the disease. Despite this, we conclude with several key examples that imagine hope otherwise. These "hopeful" alternatives show how hope might be understood not as militant affirmation, but as practices that attend to death and precarity through recognition of vulnerability. In these alternative imaginings, what is hoped for is more tangible, modest, and immediate than triumphant survival.

The Beautiful and Bald Movement, for instance, began a public campaign in 2011 to convince toymaker Mattel to mass-produce a bald Barbie doll called Hope, "in support of children living with hair loss due to chemotherapy, alopecia, trichotillomania and other autoimmune diseases." ${ }^{\prime 9}$ This demand for the Hope Barbie took the form of social-networking activism, operating primarily on Facebook, and has had overwhelming public support, with more than 150,000 fans as of March 2012..$^{70} \mathrm{~A}$ prototype of the doll that Mattel did produce sported a magnificent diamante-encrusted, black ball-gown, a pink stole, and a tiara on her proudly displayed bald head. Such a doll offers an alternative to the contemporary "makeover" imperative that compels cancer to be hidden through the maintenance of normative femininity, which is largely signified through hair, and instead actualizes the public display of cancer in its depiction of the harsh physical effects of treatments. If released on the mass market, the doll could potentially provide young girls with hope for other models of femininity. While still working within the commercial hope culture and representing dominant norms of female embodiment, Hope Barbie could simultaneously subvert norms by resignifying hair loss, reimagining beauty, and depicting a tantalizing drag or glam superhero version of Barbie-with cancer. ${ }^{71}$ The possibility of

69. "The Beautiful and Bald Movement: Decorating Domes with Love and Happiness." http://www.beautifulandbald.com.

70. "Bald Barbie Campaign Convinces Mattel to Produce New Doll." http://www .redorbit.com/news/health/ 1112505299/bald-barbie-campaign-convinces-mattel-to -produce-new-doll/.

71. Mattel produced a one-off version of the "Hope Barbie" for 4-year-old cancer patient Genesis Reyes in early 2011. The company has recently announced that it will now create a bald friend of the Barbie doll for hospital-only circulation. See "Mattel to Make 'Bald Friend of Barbie,'” http://abcnews.go.com/blogs/health/2012/03/29/mattel 
such a doll, however, was resisted by Andrew Becker, director of media relations for the ACS, who stated that the Hope Barbie would "do more harm than good for kids and parents," and that children "could ... end up being terrorized by the prospect of it [cancer] in a far outsized proportion to their realistic chances [of developing the disease]." ${ }^{72}$ Hope Barbie, for Becker (and by extension the ACS), would lead to the evacuation of hope, presumably due to the realities that the doll would embody.

A second example of alternative imaginings of hope is at work in the organization called "Hope Cancer Ministries" (HCM). ${ }^{73}$ This nonprofit, faith-based ministry provides practical care and assistance for patients, caregivers, and families living with cancer by offering services like transportation, meals, home-handymen, housekeeping, and financial support for critical needs (for example, utility bills). These services attend to the day-to-day needs and the hard realities of those affected by cancer and its accompanying treatments when, for instance, the need for a ride to chemotherapy or childcare is often more immediate than hope for the cure. In the absence of a custodial state that might attend to the concerns of those living with illness, HCM presents a necessary safety net. It moves away from individualistic framings of hope, and instead deploys faith in the service of a practical community of health. Simultaneously, such practices might be said to offer only a compromised hope because, rather than contesting neoliberal forms of depoliticized healthcare, they "band-aid" over the shortfalls of the system. Ultimately, however, hope for help in the daily practice of living with and possibly dying of cancer represents a revised vision of hope: as that which must be continually reoriented. In this sense, the hope offered by HCM dovetails with palliative-care ideology and practice that, rather than reproducing the endless "hope through treatment" and

-to-produce-bald-friend-of-barbie/. On "makeover culture" in relation to cancer, see Shelley Cobb and Susan Starr, "Breast Cancer, Breast Surgery, and the Makeover Metaphor," Social Semiotics 22:1 (2012): 83-101; on "glam" as a response to cancer makeover culture, see Shiloh Krupar, "The Biopsic Adventures of Mammary Glam: Breast Cancer Detection and the Practice of Cancer Glamor," Social Semiotics 22:1 (2012): 47-82.

72. The original blog post, "Bald Barbie is an Over-Reach," has been removed from the ASC website; however, a copy of the Becker post is available at the Jack Morton Foundation website, http://thejackmortonfoundation.org/tuesday-january-17-2012/. Becker later apologized for his post in "Bald Barbie Demand is an Over-ReachUPDATED," http://acspressroom.wordpress.com/2012/01/13/bald-barbie-demand-is -an-over-reach/.

73. See HCM's website, http://www.hopecancer.org/. 
"hope in the cure," faces death by focusing on caring, not curing and giving credence to the possibility of dying well. By promoting nonhospitalized care at the end of life, palliative care and HCM provide the dying with hope for more quality time with loved ones, pain and symptom management, emotional or spiritual support in approaching death, and, ultimately, a good death.

Finally, Bob Carey's photographic series titled "The Tutu Project" gestures toward more modest and tentative forms of hope in relation to cancer culture-wherein, as Jain has stated, "hope and exceptionalism pervade... like a shrill thread, everyone hanging on for dear life and yet still dangling." ${ }^{74}$ In this whimsical set of images, Carey photographs himself in various locales-cornfields, barren hilltops, hanging onto a climbing wall, in the middle of a street in the snow-wearing only a scant pink tulle tutu. Inspired initially by Carey's wife's diagnosis of breast cancer, the project now raises awareness and funds for breast cancer research, and might be said to stage an implicit critique of dominant breast cancer conventions. A man wearing a pink tutu calls into question the feminization of breast cancer culture; a man frolicking, prancing, bounding, or standing as a diminutive figure in an unexpected landscape (a deserted subway station, a darkened parking lot, a cow paddock) conveys a playfulness that highlights the conservatism of cancer politics; and Carey's lone and near-naked body stands at odds with the mass spectacle of cancer in the broader public sphere. Through depicting Carey's lone figure, his face generally turned from the viewer, in often absurd locations and scenarios, these alternative renderings also introduce melancholy and vulnerability into the representation of cancer and thus push away hope as relentless optimism and the conviction to survive. Instead, hope emerges as a subtle, even solitary though not an individualistic, subjunctive possibility and as a sharing of humor in times of distress and fear. As Carey has stated, "cancer has taught us that life is good, dealing with it can be hard, and sometimes the very best thing —no, the only thing — we can do to face another day is to laugh at ourselves, and share a laugh with others." ${ }^{75}$ His articulations do not prioritize the commercialization of hope, thus enabling the politics of cancer to be foregrounded. They do not represent hope as unencumbered triumphalism, but instead seek space for dealing with messiness, fragility, absurdity, and loss and attempt to foster creative and even playful forms of per-

74. Jain, "Survival Odds" (above, n. 68), p. 46.

75. See "About the Tutu Project," http://www.thetutuproject.com/about/\#.UBX nDI5rr6E. 
sistence. In one particular image, Carey stoops against a barbed-wire fence on what appears to be the deserted edges of a city. Rubbish gathered around the fence surrounds him while a Goodyear blimp floats in the sky above. Such an image might be said to ironically juxtapose the concept of elevation and the vision of the horizon (and the hope for a good year?) with limits (the barbed-wire fence), abandonment, solitude, and the detritus of daily life. Hope, here, is a practice of "artful endurance." 76

Taken together, these alternative articulations of hope still affirm life, but they do not necessarily frame that life as exclusive of death. Moreover, these other ways of hoping perform the difficult and often painful labor of persisting within the contours of the realities of cancer and the fear that can accompany it. Instead of marshaling militant hope, these kinds of hope are fragile; they show forms of mourning, maintenance work, and humor. Rather than being predicated on future orientation, they focus on grappling with the present. Ultimately, these articulations might be said to operate as critiques of the dominant conventions of biomedical hope: they intervene into and redirect the ways that hope has come to operate and be deployed to govern populations, communities, and senses of self in relation to cancer. Here, critique operates as "an instrument for those who fight, resist, and who refuse what is. . . It is a challenge directed to what is." 77 It signals a refusal to be governed "like that and at that cost"78 and an incitement to hope otherwise.

76. Krupar, Hot Spotter's Report (above, n. 41).

77. Michel Foucault, "Questions of Method," in The Foucault Effect: Studies in Governmentality, ed. Graham Burchell, Colin Gordon, and Peter Miller (Chicago: University of Chicago Press, 1991), pp. 73-86, quote on p. 84. Foucault also states that "I would therefore propose, as a very first definition of critique, this general characterization: the art of not being governed quite so much" (Michel Foucault, "What is Critique?" in The Politics of Truth, trans. Lysa Hochroth, ed. Sylvère Lotringer and Hochroth [Los Angeles: Semiotext(e), 1997], pp. 41-81, quote on p. 45).

78. Foucault, "What is Critique?" (above, n. 77), p. 45. 